\title{
The effect of windspeed on sea surface temperature retrieval from space
}

\author{
A. R. Harris, S. J. Brown and I. M. Mason \\ Mullard Space Science Laboratory, University College London, U.K.
}

\begin{abstract}
The effect of windspeed on water emissivity, whilst being negligible around normal incidence, becomes significant above angles of about $50^{\circ}$. We calculate the effect of windspeed on retrieved sea surface temperature and show that errors become significant for the potentially very accurate Along Track Scanning Radiometer (ATSR, carried on board ESA's first remote sensing satellite, ERS-1) since brightness temperatures measured at $=56^{\circ}$, as well as those measured at nadir, are used to provide improved atmospheric correction. We show that when an SST retrieval algorithm generated assuming zero windspeed is applied to brightness temperatures calculated for windspeeds of 5,10 and $15 \mathrm{~m} / \mathrm{s}$, a potential error of up to $0.4 \mathrm{~K}$ is introduced. Since coincident windspeed data can be obtained from the ERS-1 radar altimeter, accurate correction can be made for this effect and we provide a preliminary algorithm for the correction of ATSR SST data.
\end{abstract}

\section{Introduction}

Sea surface temperature (SST) is one of the most important parameters for climate research as it controls the release of heat from the ocean to the atmosphere. SST anomalies such as the El Niño-Southern Oscillation (ENSO) are responsible for wide ranging climatic effects [Folland et al., 1990], and accuracies of a few tenths of a degree are required to monitor the growth of such anomalies which are typically only a few Kelvin in magnitude. Measurement of SST for climate change purposes would ideally achieve accuracies of $<0.1 \mathrm{~K}$ over climatic zones to facilitate early detection. Remote sensing offers an important global synoptic view, and SST has been measured from space on a routine basis for more than a decade. The main instrument that has been used for this purpose is the Advanced Very High Resolution Radiometer (AVHRR), which is carried on board the National Oceanic and Atmospheric Administration (NOAA) series of meteorological sacellites, and which NOAA have used to produce their Multi-Channel SST (MCSST) monthly mean product on a global basis since 1982. There are several sources of error which degrade the accuracy of the satellite-based retrieval, the main ones are i) sensor calibration, ii) atmospheric correction, and iii) the "skin effect", with aerosol and cloud contamination also having significant effects if they are not screened out.

The absolute calibration of the AVHRR detectors may have an error of up to $0.55 \mathrm{~K}$ [Weinreb et al., 1990]. Atmospheric correction for AVHRR (potentially up to $10 \mathrm{~K}$ in the tropics, where water vapour content, the main absorbing gas, is high) is performed by using brightness temperature measurement in two (or more) differentially absorbing channels [e.g. Deschamps and Phulpin, 1980, Llewellyn-Jones et al., 1984]. Although the algorithms are inexact because they are based on approximations to the radiative transfer equation which progressively break down as the atmospheres become more absorbing, the potential accuracy is about $0.3-0.5 \mathrm{~K}$ r.m.s. globally [Harris and Mason, 1992]. In addition, the skin temperature as measured by the

Copyright 1994 by the American Geophysical Union. satellite is typically a few tenths of a degree cooler than the bulk temperature [e.g. Robinson et al., 1984], but can be up to $1 \mathrm{~K}$ cooler in extreme circumstances; this is the so-called "skin effect". NOAA SST algorithms are empirically adjusted using match-ups between satellite-measured brightness temperatures and in situ bulk temperatures [McClain et al., 1985], the average bulk - skin temperature difference is accounted for, leaving residuals of a few tenths of a degree from the skin effect. This procedure will also remove any mean internal calibration bias The end result is that, in comparisons between in situ temperature measurements and satellite SST retrievals, the r.m.s. error is $m 0.6$ $\mathrm{K}$ [McClain et al., 1985], although some fraction of this may also be due to lack of spatial and temporal coincidence between the measurements [Minnett, 1991].

It is to improve space-based retrievals of SST that the AlongTrack Scanning Radiometer (ATSR) was designed and built by a consortium led by the U.K. Rutherford Appleton Laboratory and including the Mullard Space Science Laboratory, Oxford University, the U.K Meteorological Office and Australian CSIRO. ATSR has three main improvements which are aimed at increasing the accuracy of SST retrievals. It has better calibration (maximum possible error of $<0.1 \mathrm{~K}$ over the mission lifetime,

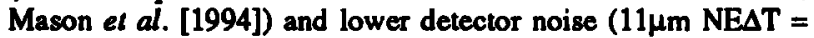
$0.03 \mathrm{~K}$ at $285 \mathrm{~K}$. Mason [1991]). In addition, the atmospheric correction is improved by having two views of the ocean surface through different atmospheric paths. The instrument first views along the satellite track in the forward direction with an incidence angle of $\approx 56^{\circ}$ and then views at nadir. Atmospheric correction error is thus reduced to as little as $\pm 0.15 \mathrm{~K}$ r.m.s. [Harris and Mason, 1992] for a global range of atmospheres.

Thus ATSR represents an opportunity to eliminate 2 of the major errors in SST retrieval from space, namely calibration and atmospheric correction (including aerosols), and the accuracy goal for spatially averaged $\left(1 / 2{ }^{\circ} \times 1 / 2\right.$ in latitude \& longitude) skin temperatures under conditions of up to $80 \%$ cloud cover is $<0.25$ K r.m.s. [Delderfield et al., 1986]. The major uncertainty that remains for retrieval of bulk SST is the skin effect, which is, as stated earlier, few tenths of a degree in magnitude, and significant effort is currently being expended on producing algorithms to correct for this. However, the effect of windspeed on surface emissivity has not been taken into account; this has an effect which is of a similar order to the skin effect and has the same sign, ie. increased windspeed will lower the observed brightness temperature.

\section{The effect of windspeed on retrieved SST}

The effect of surface roughness (chiefly determined by windspeed) on the emissivity of water has been comprehensively investigated by Masuda et al. [1988] but there have been no published attempts to take the effects into account for SST retrieval. Masuda et al. calculated the emissivity using the Cox and Munk [1955] formula for the distribution of surface slopes for a given windspeed in the open ocean and the complex refractive indices of a plane water surface (both pure and salt) for viewing angles ranging between normal and grazing incidence. Near-nadir, the effects are minimal, while larger viewing angles are more affected by windspeed. Only at relatively large viewing angles and windspeeds is there inclusion of a significant fraction of facets which are at the higher incidence angles which have emissivities that are substantially less than unity, and are 
therefore capable of reducing the average emissivity of the viewed surface ${ }^{l}$. Masuda $e l$ al. tabulated the effect for various windspeeds and viewing angles over the wavelength ranges used by satellite radiometers to measure SST, ie. $3.5-4.1 \mu \mathrm{m}$ and 8 $13 \mu \mathrm{m}$ for both salt and pure water. They also estimated the decrease in brightness temperature that would be observed at the ocean surface in the various AVHRR channels (at 3.7, 11 and $12 \mu \mathrm{m}$ ) for given viewing angles and windspeeds. In summary, the effect of windspeed on brightness temperature was $<0.2 \mathrm{~K}$ for viewing angles $<40^{\circ}$, but increased to $0.4 \mathrm{~K}$ at $50^{\circ}$ and $0.7 \mathrm{~K}$ at $60^{\circ}$.

\section{AVHRR SST retrievals}

The brightness temperatures predicted by Masuda et al did not take into account the attenuation of the atmosphere, and were not combined with SST algorithm coefficients to determine the resultant retrieval error. We have performed an analysis of the effects of windspeed on the retrieved SST by modelling the brightness temperatures that would be seen by the satellite using a line-by-line radiative transfer model developed by Albin Závody at RAL [Llewellyn-Jones et al., 1984]. A number of atmospheric profiles for the tropics ( 82 radiosondes, $0^{\circ}$ to $\pm 25^{\circ}$ latitude), midlatitudes ( 38 radiosondes, $\pm 25^{\circ}$ to $\pm 50^{\circ}$ ) and high latitudes (37 radiosondes, above $\pm 50^{\circ}$ ) were obtained from RAL. These atmospheric profiles were input into the radiative transfer model together with values of emissivity for different windspeeds, and the brightness temperatures that would be measured by the satellite for various viewing angles were calculated. Atmospheric correction coefficients were generated by regression of the surface temperatures against the predicted brightness temperatures for emissivities corresponding to $0 \mathrm{~m} / \mathrm{s}$ windspeed, yielding equations of the form:

$$
\mathrm{T}_{\mathrm{S}}=a_{0}+a_{1} \mathrm{~T}_{11}+a_{2} \mathrm{~T}_{12}
$$

where $\mathrm{T}_{S}$ is the predicted surface temperature, $a_{0}, a_{1}$ and $a_{2}$ are the algorithm coefficients $\left(a_{1}\right.$ and $a_{2}$ sum to $\left.\approx 1\right)$ and $T_{11}$ and $T_{12}$ are the modelled brightness temperatures observed by the satellite in the $11 \mu \mathrm{m}$ and $12 \mu \mathrm{m}$ channels. These coefficients were then applied to brightness temperatures calculated for windspeeds of 5,10 and $15 \mathrm{~m} / \mathrm{s}$. The resultant errors for the high-latitude band are shown in Fig. 1.

The first thing to note about the range of the effect is that it is smaller in magnitude than that predicted by Masuda $e t$ al. for the reduction in brightness temperature for a single channel. The main reason for this is that the atmosphere absorbs some of the signal from the surface, thus reducing the effect of any change in the surface emittance. In addition, the change in emissivity with windspeed is similar, ie. about $0.8 \%$ from $0 \mathrm{~m} / \mathrm{s}$ to $15 \mathrm{~m} / \mathrm{s}$, for both the $11 \mu \mathrm{m}$ and $12 \mu \mathrm{m}$ channels, so there is no amplification due to the algorithm coefficients.

The results show that the effect on AVHRR retrievals of SST is to lower the retrieved temperature, and is $<0.1 \mathrm{~K}$ below an incidence angle of $50^{\circ}$, ie. the central $55 \%$ of the ground swath. Above $50^{\circ}$ the reduction in SST increases to several tenths of a $\mathrm{K}$ at the maximum incidence angle of $68.8^{\circ}$, being about $0.4 \mathrm{~K}$ at $60^{\circ}$. It should be noted that MCSST data do not include retrievals based on brightness temperatures measured above a viewing angle of $53^{\circ}$ [McClain et al., 1985].

Although the errors are significant for large viewing angles, the bias caused by windspeed-induced emissivity error is less than the main source of error for AVHRR retrievals at such angles, namely the atmospheric correction. Total retrieval errors are of the order of $\pm 0.6 \mathrm{~K}$ r.m.s., thus the windspeed effect does not make a dominant contribution.

\footnotetext{
${ }^{1}$ The downward emission from the atmosphere will also increase with viewing angle and will therefore tend to enhance the emissivity of larger incidence angle facets and reduce the emissivity of facets at smaller incidence angles.
}

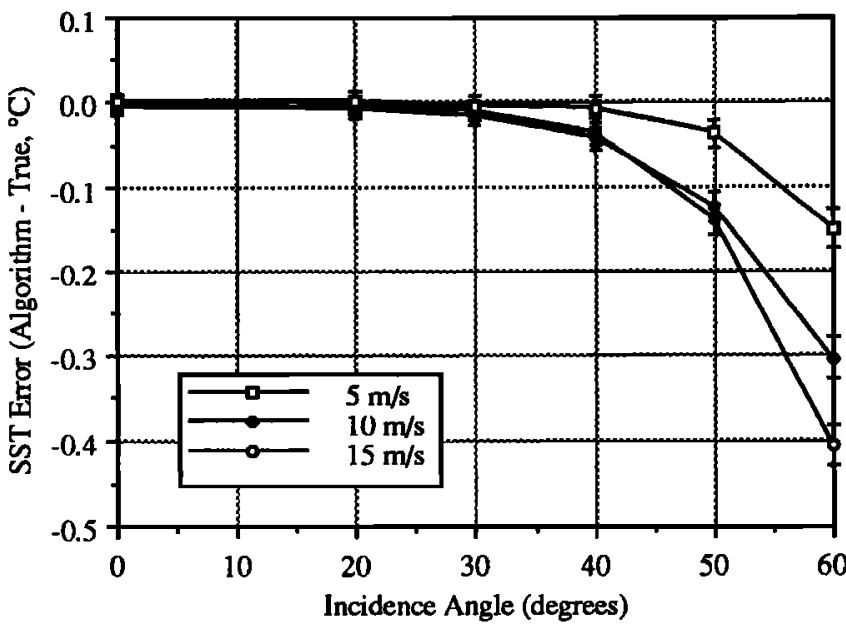

Figure 1. The effect of viewing angle and windspeed on AVHRR SST retrievals for high latitudes $\left( \pm 50^{\circ}- \pm 75^{\circ}\right)$. Each point represents the mean SST error calculated for all the atmospheric profiles (see Fig. 2 for typical spread); the error bar represents the error on this mean. The effect is reduced for other latitude regions.

\section{ATSR SST retrievals.}

ATSR, as we have seen, has the potential to retrieve SSTs to an r.m.s. accuracy of better than $\pm 0.25 \mathrm{~K}$. The instrument makes use of data viewed at two different angles to provide an improved atmospheric correction, but this renders SST retrieval from the instrument vulnerable to the effects of windspeed upon emissivity across the entire swath. It is the along-track data, viewed at the relatively high incidence angle of $\approx 56^{\circ 2}$, that are sensitive to different in windspeed, whereas the nadir-view data are insensitive. We have repeated the calculations described earlier for the ATSR instrument, with the difference that the SST retrieval algorithm now includes terms for the forward view temperatures and thus has the form

$$
\mathbf{T}_{S}=b_{0}+b_{1} \mathbf{T}_{11 \mathrm{n}}+b_{2} \mathrm{~T}_{12 \mathrm{n}}+b_{3} \mathrm{~T}_{11 \mathrm{f}}+b_{4} \mathrm{~T}_{12 \mathrm{f}}
$$

where subscript $n$ and $f$ denote that brightness temperatures were derived from the nadir and forward views respectively ${ }^{3}$. SST retrieval coefficients, derived using emissivities corresponding to $0 \mathrm{~m} / \mathrm{s}$ windspeed, were applied to brightness temperatures calculated for emissivities corresponding to windspeeds of 5,10 and $15 \mathrm{~m} / \mathrm{s}$ as before, and the results, again for high latitudes, are shown in Fig. 2. The results of applying SST retrieval coefficients, derived using emissivities corresponding to $0 \mathrm{~m} / \mathrm{s}$ windspeed, to brightness temperatures calculated for emissivities corresponding to windspeeds of 5,10 and $15 \mathrm{~m} / \mathrm{s}$ are shown in Figure 2. The effect of increasing windspeed is to increase the retrieved SST (i.e. opposite from AVHRR) since the coefficients $b_{3}$ and $b_{4}$ that multiply the forward view brightness temperatures (i.e. those which are affected by windspeed) sum to $\approx-1$. The effect has a range of $0.4 \mathrm{~K}$ at the centre of the swath and decreases slightly towards the edge. The windspeed range was chosen to be typical of the range of surface winds over the ocean.

To illustrate this, and to assess the geographical distribution of the potential SST errors, we have produced the 3-day average windspeed over the ocean for an arbitrarily chosen period, using windspeed estimates contained in the ERS-1 radar altimeter fast delivery product. The interpolation was performed with a land mask and the data were filtered to remove contamination from sea ice; the result of this process is shown in Fig. 3. Firstly, the range of windspeeds observed in the plot spans that chosen for the simulation studies. In addition, the wind patterns that are due to major elements of the global atmospheric circulation are clearly evident. In particular, high windspeed areas are usually 


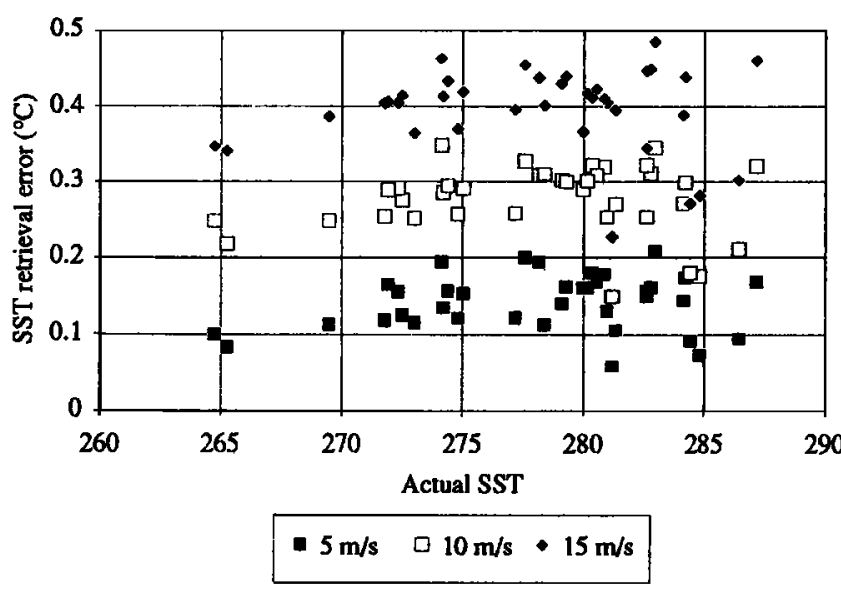

Figure 2. The effect of windspeed on ATSR dual-view multichannel SST retrievals for high latitudes $\left( \pm 50^{\circ}- \pm 75^{\circ}\right)$. The spread for each windspeed is related to atmospheric transmittance, with the effect being reduced for more absorbing atmospheres. This is the reason why the effect is reduced for atmospheres from lower latitudes (see Fig. 4).

adjacent to areas of low windspeed, such areas typically have differences of $10 \mathrm{~m} / \mathrm{s}$ in windspeed between them. In order to estimate the effect of windspeed on the $1 / 2{ }^{\circ}$ spatially averaged SST product that is generated for ATSR, we have calculated the effect of windspeed on SST retrieval coefficients for three latitude bands in the same way as is done for ATSR processing [Závody et al., 1994]. These coefficients were applied to brightness temperatures calculated for 5,10 and $15 \mathrm{~m} / \mathrm{s}$ windspeeds as before, and the relationship between windspeed and SST retrieval error was obtained in each case as a simple linear $\mathrm{fit}^{4}$ (Fig. 4). Note that while the effect of windspeed is similar for mid and high latitudes, the effect for tropical atmospheres is significantly reduced. The reason for this is that the atmospheric absorption along-track (the view that is affected by windspeed) is so great that as little as $4 \%$ of the signal is coming from the surface, so changes in the surface-emitted radiance due to emissivity changes are almost completely attenuated.

The ATSR $1 / 2^{\circ}$ spatially averaged SST product uses retrieval algorithm coefficients that are linearly interpolated between the centres of two adjacent latitude bands [Závody, pers. comm., 1994], so we have calculated the SST error based on both windspeed and latitude, since the effect of windspeed is different for the three latitude regions, being a maximum for high latitudes. The result of converting the windspeed values to SST retrieval error is shown in Fig. 5. Note that the effect is greatly reduced for the tropics, but that the North Atlantic and Southern Ocean still display significant retrieval error.

\footnotetext{
${ }^{2}$ The true $1 / 2$ cone angle of ATSR is $23.63^{\circ}$ rather than the early design value of $23.45^{\circ}$, thus the along-track viewing angle is therefore $55.6^{\circ}$ rather than $55.1^{\circ}$, and a bias of $0.1 \mathrm{~K}$ results if the old angle is used.

3 The algorithm has only been derived for the 11 \& $12 \mu \mathrm{m}$ channels because a) this is the same as ATSR during the daytime, and b) the $3.7 \mu \mathrm{m}$ detector failed in May 1992.

${ }^{4}$ We have also performed a "worst case" study of the effect of the change in reflected downward emission from the atmosphere (footnote 1) with windspeed and found that the effect is decreased by only $\approx 15 \%$.
}

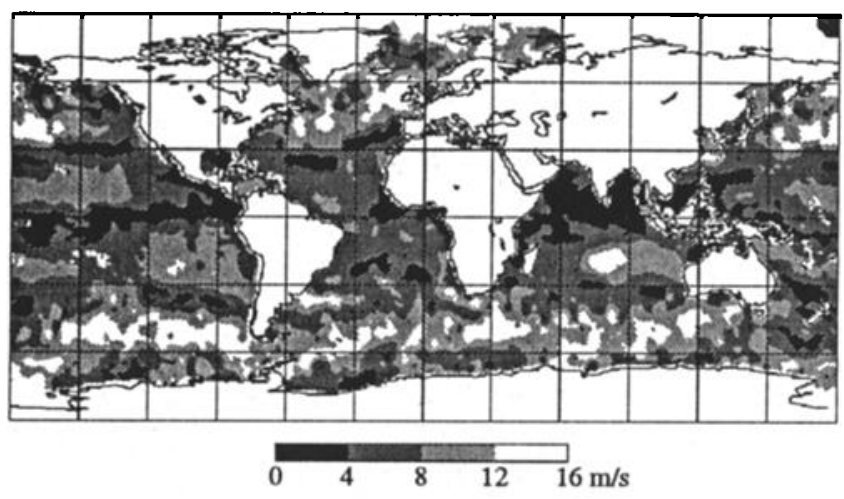

Figure 3. Ocean windspeeds for $4^{\text {th }}-6^{\text {th }}$ April 1992 derived from ERS-1 radar altimeter fast delivery product. The data have been filtered to remove sea ice contamination before smoothing. The mean windspeed (averaged over $1 / 2^{\circ}$ squares and hence biased to high latitudes) is $7.4 \mathrm{~m} / \mathrm{s}$.

\section{Conclusions}

The effect of windspeed on emissivity has been known for some time, but no correction for it has been incorporated into SST retrieval algorithms. The reasons for this appear to be i) the effect is known to be fairly small, and, in the case of AVHRR, the effect is not the dominant source of error, ii) the effect is very small below $50^{\circ}$ incidence angle, iii) coincident windspeed data are not always available, and obtaining them where they do exist would complicate the processing. In the case of ATSR, the effect is always potentially significant, a) because of the instrument's excellence in dealing with other sources of error, and b) because data from the forward view at $56^{\circ}$ incidence are used to obtain the best atmospheric correction. We have produced simple algorithms which, together with appropriate (e.g. ERS-1 radar altimeter) windspeed data, can be utilised by end-users of ATSR SST $1 / 2^{\circ}$ spatially averaged (and other) products. It should be pointed out that the dual-view is not always used for SST retrieval, particularly in the presence of heavy cloud, and correction for windspeed is not necessary for SSTs derived from nadir-only brightness temperatures; information on the use of nadir-only derivation is provided in the ATSR SST products.

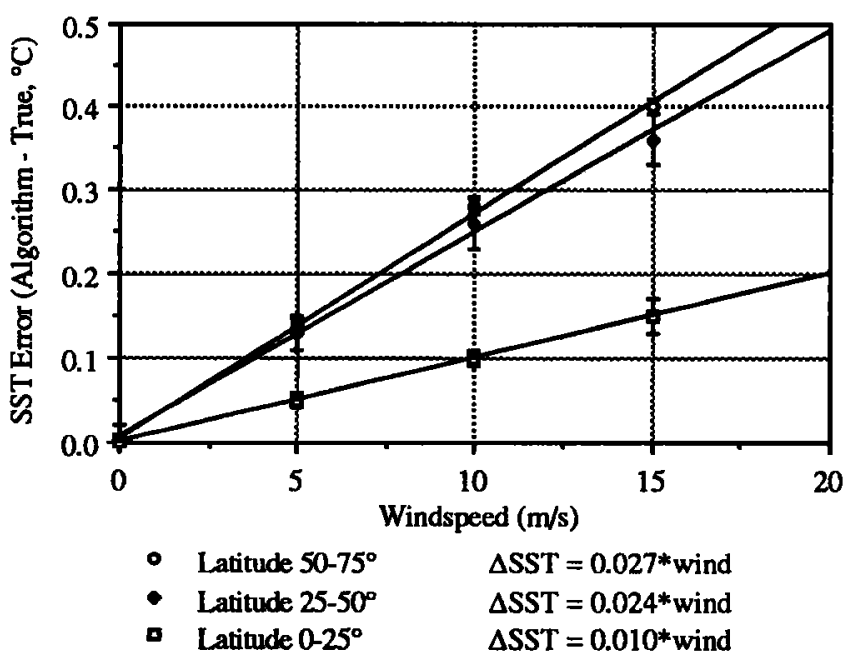

Figure 4. Plot of ATSR SST retrieval error against windspeed for the three latitude bands. The effect is greatest for the high latitude atmospheres which have the least absorption, and is greatly reduced for the tropical atmospheres where atmospheric absorptions are high. 


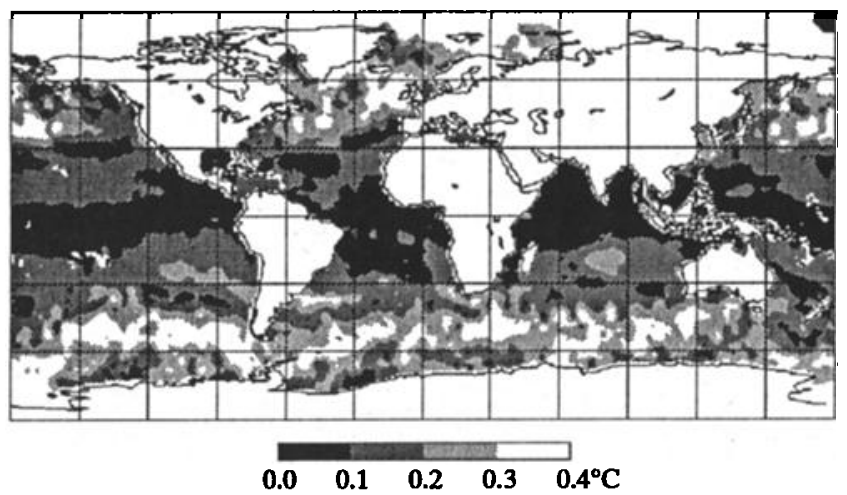

Figure 5. Plot showing the result of converting the ocean windspeeds to ATSR SST retrieval error via the simple relationships shown in Fig. 3. The windspeed correction coefficents have been interpolated between the various latitude bands.

The effect is of a similar order to that of the much researched skin effect, and presents a similar dependence on windspeed, although is opposite in sign for ATSR dual-view. In addition, the patterns of ocean windspeed are related to fundamental parts of the atmospheric circulation, thus emissivity-related errors in windspeed retrieval will be geographically biased and change with the seasons. Interest is now being shown in comparing ATSR retrievals with global bulk temperatures to obtain the skin - bulk temperature difference and thereby estimating the net heat exchange at the surface; such measurements will be crucially dependent on skin temperatures with no windspeed bias. The effect will also be important for the study of phenomena such as the ENSO which are manifested by differences in windspeed as well as SST, as well as for early climate change detection. Since coincident windspeed data are readily available from instruments that are carried on board ERS-1 along with ATSR, it is now possible to correct for this effect before attempting the more difficult task of estimating the magnitude of the skin - bulk temperature difference.

Acknowledgements. The authors would like to thank Albin Závody of RAL for supplying the radiative transfer code and discussions concerning ATSR processing, and the U.K. Meteorological Office as original suppliers of the radiosonde data. The ERS-1 radar altimeter data were provided by the French Processing and Archiving Facility. ERS-1 data are copywright European Space Agency. Simon Brown is funded by the Science and Engineering Research Council.

\section{References}

Cox, C., and Munk, W., Some problems in optical oceanography. $J$. Marine Res., 14, 63-78, 1955.

Delderfield, J., Llewellyn-Jones, D.T., Bernard, R., de Javel, Y., Williamson, E.J., Mason, I.M., Pick, D.R., and Barton, I.J., The Along
Track Scanning Radiometer (ATSR) for ERS-1. Instrumentation for optical remote sensing from space, SPIE 589, pp 114, 1986.

Deschamps, P.Y., and Phulpin, T., Atmospheric correction of infrared measurements of sea surface temperature using channels at 3.711 and $12 \mu \mathrm{m}$. Bound. Layer Met., 18, 131-143, 1980.

Folland, C.K., Karl, T.R., and Vinnikov, K. Ya., Observed climate variations and change, in Climate Change - The IPCC Scientific Assessment, edited by J.T. Houghton, G.J. Jenkins and J.J. Ephraums, pp 195-238, Cambridge University Press, Cambridge, 1990.

Harris, A.R., and Mason, I.M., An extension to the split-window technique giving improved atmospheric correction and total water vapour. Int. J. Rem. Sens., 13, № 5, 881-892, 1992.

Llewellyn-Jones, D.T., Minnett, P.J., Saunders, R.W., and Závody, A.M., Satellite multichannel infrared measurements of sea surface temperature of the N.E. Atlantic ocean using AVHRR/2. Quart. $J$. Roy. Met. Soc., 110, 613-631, 1984.

Mason, G., Test and calibration of the Along Track Scanning Radiometer, a satellite designed to measure sea surface temperature, $\mathrm{PhD}$ Thesis, University of Oxford, 1991.

Mason, I.M., Sheather, P.H., Bowles, J.A. and Davies, G., Black body calibration sources of high accuracy for a spaceborne infrared instrument; the Along Track Scanning Radiometer, in preparation.

Masuda, K., Takashima, T., and Takayama, Y., Emissivity of pure and sea waters for the model sea surface in the infrared window regions. Rem. Sens. Env., 24, 313-329, 1988.

McClain, E.P., Pichel, W.G., and Walton, C.C., Comparative performance of AVHRR-based multichannel sea surface temperatures. J. Geophys. Res., 90, № C6, 11,587-11,601, 1985.

Minnett, P.J., Consequences of sea surface temperature variability on the validation and applications of satellite measurements. J. Geophys. Res., 96, № NC10, 18,475-18,489, 1991.

Robinson, I.S., Wells, N.C., and Chamock, H., The Sea Surface Thermal Boundary Layer and its Relevance to the Measurement of Sea Surface Temperature by air-borne and space-borne Radiometers. Int. J. Rem. Sens., 5, $\mathrm{N}^{2} 1,19-45,1984$.

Weinreb, M.P., Hamilton, G., Brown, S., and Koczor, R.J., Nonlinearity corrections in calibration of Advanced Very High Resolution Radiometer infrared channels. J. Geophys. Res., 95, No C5, 7,3817,388, 1990.

Závody, A.M., Gorman, M.R., Lee, D.J., Eccles, D., Mutlow, C.T., and Llewellyn-Jones, D.T., The ATSR processing scheme developed for the EODC, Int J. Rem. Sens. , 15, № 4, 827-843, 1994.

A. R. Harris, S. J. Brown and I. M. Mason, Department of Space and Climate Physics, University College London, Mullard Space Science Laboratory, Holmbury St. Mary, Dorking, Surrey, RH5 6NT, U.K.
Received: 8 February 1994

Revised: 28 April 1994

Accepted: 9 May 1994 